\title{
The Role of I and B in Peritonitis Associated with the Nephrotic Syndrome of Childhood ${ }^{1}$
}

\author{
DOUGLAS G. MATSELL AND ROBERT J. WYATT \\ Division of Pediatric Nephrology, Department of Pediatrics, University of Tennessee, Memphis, Tennessee 38163
}

\begin{abstract}
Children with nephrotic syndrome (NS) are susceptible to bacterial infections, including primary bacterial peritonitis. Immunologic abnormalities associated with NS include low serum levels of the complement proteins I and B of the alternative complement pathway. We developed a novel and highly sensitive enzyme immunoassay using murine MAb to I and $B$ to quantitate urinary concentrations of these proteins. We studied 22 patients with minimal change NS, including seven with a history of peritonitis (1.6 \pm 0.3 episodes, mean \pm SEM) and 15 without such a history. The two groups did not differ significantly in age, sex, race, age at onset of disease, or duration of disease. Children with minimal change NS complicated by peritonitis had 1 ) increased urinary excretion of both $I(p<0.05)$ and $B(p<0.05)$ in relapse versus remission, 2) greater excretion of $I$ in both relapse $(p<$ $0.01)$ and remission $(p<0.05)$ compared with patients without peritonitis, 3 ) greater excretion of $B$ in relapse compared with patients without peritonitis $(p<0.05)$, and 4) decreased plasma levels of I compared with patients without peritonitis and controls $(p<0.01)$ and decreased plasma levels of B compared with controls. Increased urinary excretion of $I$ correlated with decreased plasma levels of $I(r=0.88, p<0.001)$. These data support our initial hypothesis that depressed plasma concentrations of these proteins of the alternative complement pathway may predispose patients with minimal change NS to peritonitis and that urinary loss of these proteins is a tenable mechanism. (Pediatr Res 34: 84-88, 1993)
\end{abstract}

\section{Abbreviations}

NS, nephrotic syndrome

MCNS, minimal change nephrotic syndrome

ACP, alternative complement pathway

EIA, enzyme immunoassay

The basis of the predisposition of children with NS to infectious complications of their disease is not fully understood. In the preantibiotic era, infection and bacterial sepsis were frequent causes of death in patients with NS $(1,2)$. Primary bacterial peritonitis is perhaps the most important and serious complication among children with NS, and it remains a significant cause of morbidity, occurring in up to $17 \%$ of all children with NS $(3,4)$.

Received June 30, 1992; accepted February 15, 1993.

Correspondence and reprint requests: Dr. R. J. Wyatt, Department of Pediatrics, LeBonheur Children's Medical Center, 848 Adams Ave., Memphis, TN 38103.

Supported by a grant from LeBonheur Children's Medical Center. Dr. Matsell was a fellow of the Kidney Foundation of Canada during the period of this study.

' Presented at the annual meeting of the Canadian Pediatric Society in Quebec City, Canada, September 1991.
Among the numerous immunologic abnormalities associated with active NS, defects in humoral immunity play an important role in this relative immunosuppression. Disorders of the complement system include depression of serum concentrations of the alternative pathway proteins, I and B (5), and presumably impairment of $\mathrm{C} 3 \mathrm{~b}$ generation and host opsonization.

Dual monoclonal assays, both EIA and radioassays have been used in the measurement of serum and plasma concentrations of $\mathrm{B}$. In the case of the radioassay, using a ${ }^{125} \mathrm{I}$-labeled $\mathrm{MAb}$ to $B_{a}$, the sensitivity was to $30 \mu \mathrm{g} / \mathrm{L}$ (6). Sensitivities of the various EIA for measurement of $B_{b}$ are in the same range, with a lower limit for the $\mathrm{B}_{\mathrm{b}}$ EIA to $10 \mu \mathrm{g} / \mathrm{L}$ (7). Previous attempts at detection of $I$ and $B$ in urine samples using standard radial immunodiffusion in agar gels were unsuccessful, owing to the relatively low sensitivity of this technique. The primary objective of this study was to develop a sensitive assay to quantitate the urinary excretion of I. Similar to previous EIA for quantitation of B in plasma and serum, we developed an EIA for the quantitation of urinary $B$ excretion. In addition, we examined the differences in the urinary excretion of these proteins among patients with NS complicated by peritonitis, patients with uncomplicated NS, and normal healthy controls.

\section{MATERIALS AND METHODS}

Definitions. Nephrotic syndrome was characterized by edema, hypoalbuminemia, hypercholesterolemia, and a urinary protein excretion of $>40 \mathrm{mg} / \mathrm{m}^{2} / \mathrm{h}$. Relapse was defined as the reoccurrence of proteinuria $>3 \mathrm{~g} / \mathrm{L}(300 \mathrm{mg} / \mathrm{dL}$ ) by Multistix (Miles Laboratories, Elkhart, IN) for 3 consecutive d, with edema and/ or hypoalbuminemia in a case of previously diagnosed NS. In a case of previously diagnosed NS, the absence of edema, hypoalbuminemia, hypercholesterolemia, and $<0.3 \mathrm{~g} / \mathrm{L}(30 \mathrm{mg} / \mathrm{dL})$ of protein by urine dipstick constituted a remission. Steroid responders had resolution of their proteinuria, edema, hypoalbuminemia, and hypercholesterolemia after an initial course of prednisone with fewer than four relapses per year, all responsive to prednisone therapy. Steroid-responsive frequent relapsers were responsive to prednisone but had more than four relapses per year. Steroid-dependent frequent relapsers had more than four relapses per year, responsive to prednisone, but the relapses occurred while patients were on tapering doses of prednisone, or within $2 \mathrm{wk}$ of its discontinuation. Steroid-resistant patients exhibited incomplete or no response to prednisone and usually required additional drug therapy. The diagnosis of peritonitis was based on the clinical signs of abdominal tenderness and peritoneal irritation. Examination of the peritoneal fluid yielded a positive bacterial culture and/or $>250$ white blood cells per high-power field by microscopy.

Patients. We prospectively studied 22 patients with idiopathic NS, or MCNS at LeBonheur Children's Medical Center, Memphis, TN. Informed written consent was obtained, and the study protocol was approved by the University of Tennessee, Memphis Institutional Review Board. Patients with biopsy histology other than MCNS were excluded from the study. Seven patients were identified with a history of at least one episode of documented 
peritonitis and were enrolled in the peritonitis group. Four patients were studied both in remission and relapse, two were studied only in relapse, and one was studied only in remission. The mean interval between the most recent episode of peritonitis and inclusion into the study was $11.3 \mathrm{mo}$, with a range of 0.03 to $47 \mathrm{mo}$. Fifteen patients were included in the group without peritonitis. In this group, seven patients were studied in relapse, and eight different patients were studied in remission. Six healthy child volunteers served as controls for the urinary studies. Sampling was performed at routine out-patient follow-up visits and on occasion during hospitalization. On only one occasion in one patient were samples obtained during an episode of peritonitis.

There were no significant differences between the two groups with respect to age at the time studied, age at onset of NS, duration of disease when studied, and gender and race ratios (Table 1). Of note was the fact that the majority of patients with NS and a history of peritonitis were steroid-resistant at the time of study (Table 2). In contrast, the majority of the patients without peritonitis had shown or were showing some response to prednisone therapy.

$E I A$. EIA using a three-antibody technique were developed for the quantitation of urinary concentrations of both I and B. Aliquots of freshly voided urine were centrifuged at $1500 \mathrm{rpm}$ for $5 \mathrm{~min}$, and the supernatant was decanted, collected, and stored at $-20^{\circ} \mathrm{C}$ until used.

A murine MAb to human I protein (Quidel, San Diego, CA) was diluted to a concentration of $1.25 \mathrm{mg} / \mathrm{L}$ in a coating buffer

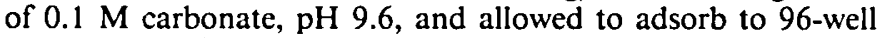
polystyrene microtiter plates (Corning, Houston, TX) for $18 \mathrm{~h}$ at $4^{\circ} \mathrm{C}$. The coating solution was removed, and wells were blocked with a diluting buffer of $0.05 \%$ Tween-20 and $0.25 \%$ BSA in PBS for $1 \mathrm{~h}$ at room temperature. After removal of the blocking solution, $50 \mu \mathrm{L}$ of undiluted urine samples were added to each well. The plates were then covered and incubated at $37^{\circ} \mathrm{C}$ for 30 min followed by washing with a buffer of $0.05 \%$ Tween-20 in PBS. Fifty $\mu \mathrm{L}$ of polyclonal goat anti-human factor I antisera, prepared as described previously (8) and diluted to $1: 2000$ in diluting buffer, were added and incubated at $37^{\circ} \mathrm{C}$ for $30 \mathrm{~min}$. After washing, $100 \mu \mathrm{L}$ of an affinity-purified horseradish peroxidase-conjugated donkey anti-goat-antibody (Jackson Immunoresearch, West Grove, PA) in a dilution of $1: 8000$ were added and inculated for $30 \mathrm{~min}$ at $37^{\circ} \mathrm{C}$. Plates were then washed thoroughly, and $50 \mu \mathrm{L}$ of the peroxidase substrate solution $2^{\prime}$ azidino-di-(3-ethylbenzothiazdine sulfonate) was added. Absorbance was then read at $405 \mathrm{~nm}$ at $15 \mathrm{~min}$ using an automated microtiter plate spectrophotometer (Bio-Tek EL 312, Bio-Tek Instruments, Inc., Burlington, VT). Standards consisted of puri-

Table 1. Patient profile

\begin{tabular}{lccc}
\hline & $\begin{array}{c}\text { Peritonitis } \\
(n=7)\end{array}$ & $\begin{array}{c}\text { No } \\
\text { peritonitis } \\
(n=15)\end{array}$ & $p$ \\
\hline Age at study $(\mathrm{y})$ & $7.7 \pm 1.3$ & $7.1 \pm 0.9$ & $\mathrm{NS}$ \\
Age at onset $(\mathrm{y})$ & $4.3 \pm 1.0$ & $3.9 \pm 0.6$ & $\mathrm{NS}$ \\
Disease duration $(\mathrm{y})$ & $3.4 \pm 1.0$ & $3.3 \pm 0.6$ & $\mathrm{NS}$ \\
Sex (male/female) & 1.3 & 1.3 & $\mathrm{NS}$ \\
Race (black/Caucasian) & 1.3 & 1.0 & $\mathrm{NS}$ \\
Peritonitis episodes & $1.6 \pm 0.3$ & 0 & 0.0001 \\
\hline
\end{tabular}

Table 2. Clinical response to prednisone

\begin{tabular}{lcc}
\hline & Peritonitis & $\begin{array}{c}\text { No } \\
\text { peritonitis }\end{array}$ \\
\hline $\begin{array}{l}\text { Steroid-responsive } \\
\begin{array}{l}\text { Steroid-responsive frequent } \\
\text { relapser }\end{array}\end{array}$ & $1(14 \%)$ & $5(33 \%)$ \\
$\begin{array}{l}\text { Steroid-dependent frequent } \\
\text { relapser }\end{array}$ & $1(14 \%)$ & $4(27 \%)$ \\
Steroid-resistant & 0 & $4(27 \%)$ \\
\hline
\end{tabular}

fied I protein (Quidel) with serial dilutions down to $80 \mu \mathrm{g} / \mathrm{L}$. Samples and standards were analyzed in triplicate.

The identical procedure was used for quantitation of urinary $\mathrm{B}$, using a murine MAb to native human B protein (Quidel) in a concentration of $1.25 \mathrm{mg} / \mathrm{L}$, a goat anti-human $B$ polyclonal antibody (8) in a dilution of $1: 1000$, and a horseradish peroxidase-conjugated donkey anti-goat IgG (Jackson) in a dilution of $1: 8000$. Standards consisted of serial dilutions of purified B protein (Quidel).

Plasma concentrations of factors I and B. EDTA plasma was collected and frozen at $-70^{\circ} \mathrm{C}$ until used. The plasma concentrations of I and B were determined by radial immunodiffusion using goat antisera incorporated into agarose. Methods for production of the goat antisera and standards have been described previously (6). The adult normal range for serum I and B concentrations was \pm 2 SD from the mean of 100 healthy adult controls, as previously published (9).

Urinary concentration of creatinine. Urinary creatinine concentration was determined with a Beckman Creatinine Analyzer II chemistry analyzer (Beckman Instruments Inc., Fullerton, CA). Undiluted urine samples were assayed in duplicate.

Statistical analysis. Demographic differences between patient groups were determined by unpaired $t$ test and by $\chi^{2}$ analysis where appropriate. Differences between groups for urinary concentrations of complement proteins were determined by MannWhitney $\mathrm{U}$ test and for serum concentrations by unpaired $t$ test. A $p<0.05$ was considered statistically significant. Excretion of the complement proteins was expressed as a ratio of urinary protein to urinary creatinine concentration. Analysis was performed on a Macintosh LC II personal computer, using the commercial statistical software package Statview 512 (Brainpower Inc., Calabasas, CA).

\section{RESULTS}

Urinary I and B excretion. Children with NS with a history of peritonitis excreted significantly more $I$ and $B$ in their urine during relapse than during remission and than healthy controls (Fig. 1). Urinary excretion of I in nephrotic children without peritonitis was significantly greater in relapse than in remission. but not significantly different than in controls, whereas the urinary excretion of $B$ in relapse was not significantly different than in remission or than in controls. Furthermore, children with NS with peritonitis excreted significantly greater concentrations of I than children without peritonitis, both in remission and in relapse, and greater concentrations of $B$ in relapse. The complement protein B was not detectable in the urine of either patient group when patients were in remission of their NS.

Although there were no statistically significant differences in urinary creatinine concentrations among the groups, the peritonitis group in relapse, in fact, had the highest mean urinary creatinine concentration $[1.25 \mathrm{~g} / \mathrm{L}(125 \mathrm{mg} / \mathrm{dL})]$ compared with the peritonitis group in remission $[0.8 \mathrm{~g} / \mathrm{L}(80 \mathrm{mg} / \mathrm{dL})]$, the nonperitonitis group in relapse and remission $[0.81,0.79 \mathrm{~g} / \mathrm{L}$ $(81,79 \mathrm{mg} / \mathrm{dL})]$, and the controls $[0.64 \mathrm{~g} / \mathrm{L}(64 \mathrm{mg} / \mathrm{dL})]$. Thus, the protein/creatinine ratio in the peritonitis in the relapse group was not artifactually elevated because of a low urinary creatinine concentration.

Plasma I and B concentrations. The children with NS in our study as a group had significantly decreased plasma concentrations of I and B during relapse of their disease when compared with adult controls. From this group, patients with NS and a history of peritonitis had significantly lower plasma concentrations of I and B during relapse than controls, whereas mean plasma concentrations of $I$ and $B$ in patients without peritonitis did not differ significantly from controls. Furthermore, plasma concentrations of I were significantly lower in patients with a history of peritonitis than in those without such a history (Fig. 2). 


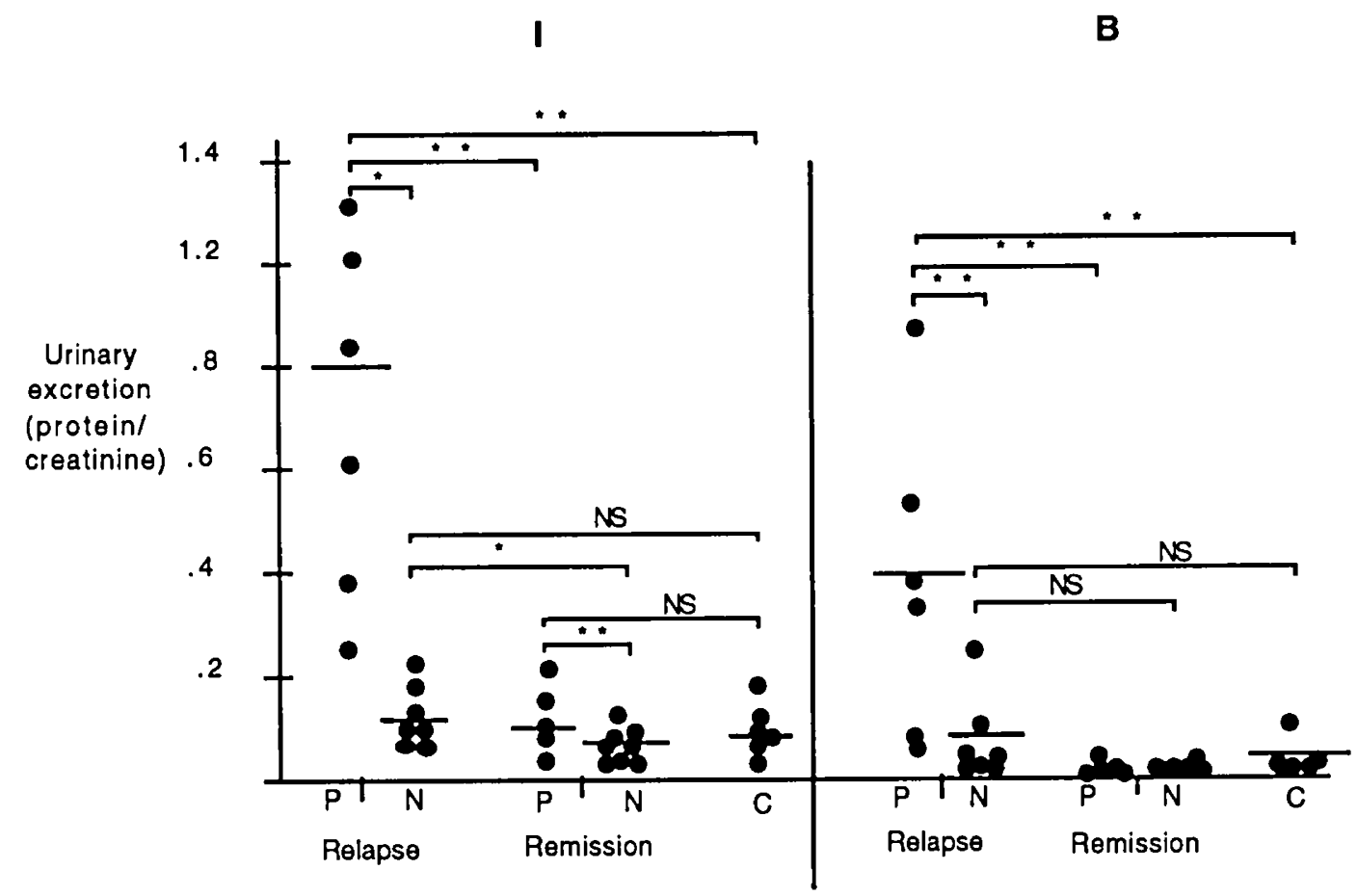

Fig. 1. Urinary excretion of I and B. The values for urinary excretion of I and B (corrected for urinary creatinine) are plotted for patients with a history of peritonitis $(P)$, no history of peritonitis $(N)$, and controls $(C)$, in both relapse and remission. The points represent unpaired data, and the points in each column represent values from different patients. $N S$, not significant. ${ }^{*}, p<0.01 ;{ }^{* *}, p<0.05$. The five points in the peritonitis group in remission include two patients who were steroid-responsive and three other patients who went on to second-and third-line therapy to induce remission.

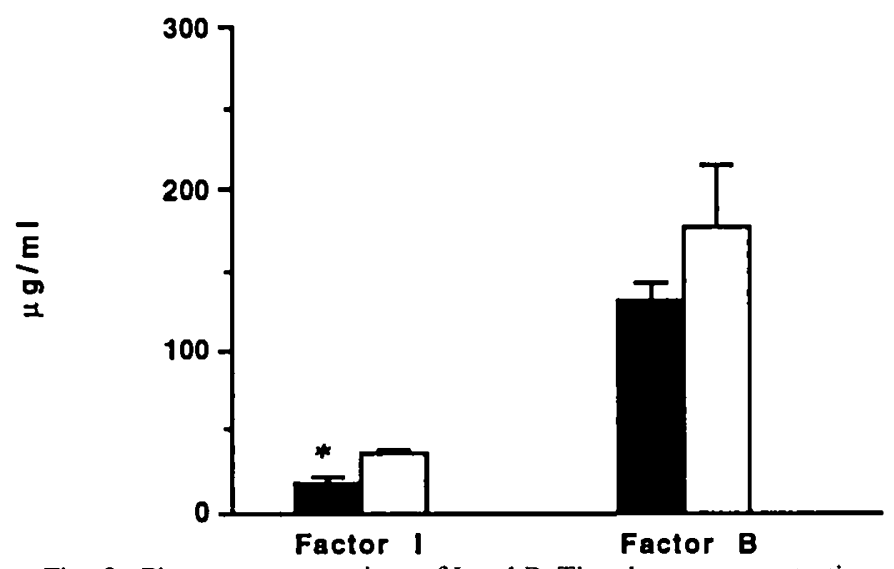

Fig. 2. Plasma concentrations of I and B. The plasma concentrations for I and B during relapse are plotted for patients with a history of peritonitis $(\square ; n=5)$, and for patients with no history of peritonitis $(\square$; $n=7){ }^{*}, p<0.01$.

Relationship between urinary and plasma concentrations of $I$. Using linear regression and logarithmic transformation, plasma concentrations and urinary excretion of I showed an inverse linear relationship (Fig. 3). Presumably, as the urinary excretion of I increases, the plasma concentration decreases.

\section{DISCUSSION}

We developed a novel, specific, and sensitive EIA that allowed us to detect and quantitate the urinary excretion of the complement proteins I and $\mathrm{B}$. With the use of murine capture MAb, we were able to detect these proteins in nanogram concentrations in the urine. This has never been previously reported, and the urinary losses of these proteins in various conditions, particularly in active NS, to this point have been speculative $(5,10,11)$.

Immunologic abnormalities associated with active NS are well described, including various complement derangements such as

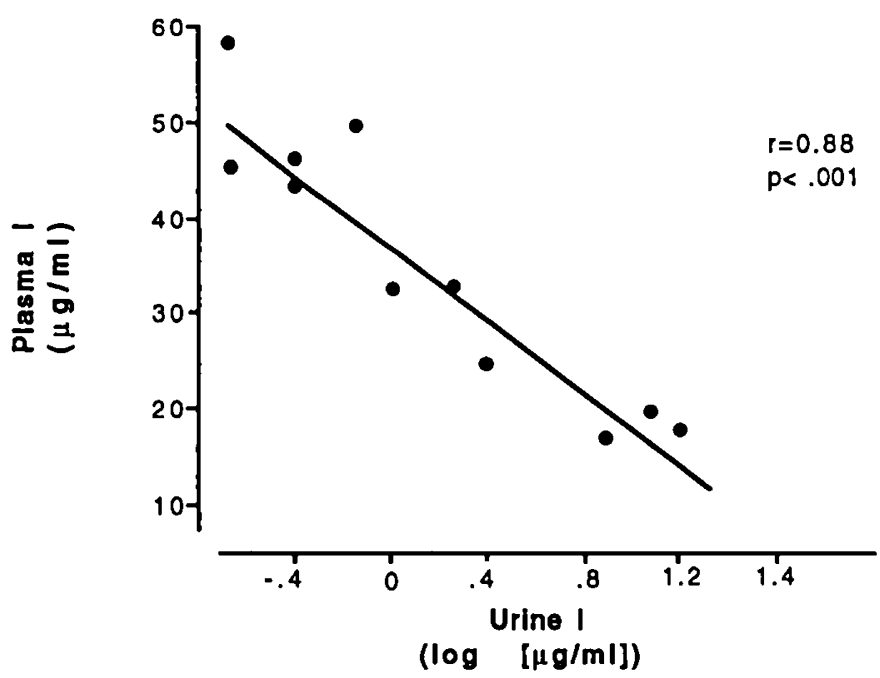

Fig. 3. The correlation of plasma and urinary concentrations of $I$. The plasma concentration of $I$ is plotted versus the urinary excretion of I in the same patient. $r=0.88 ; p<0.001$.

depression of the complement proteins I and B of the ACP and depression of $\mathrm{Clq}$ and $\mathrm{C} 2$ of the classical pathway of complement $(5,8,11,12)$. Presumably, complement activation is not occurring in idiopathic nephrosis or MCNS, as serum C3 concentration is normal and immune deposits containing $\mathrm{C} 3$ are not found by immunofluorescence histology on renal biopsy. However, the precise mechanism of depression of I and B is not known. Based upon the relatively small molecular weights of $I$ and B, 88 and $93 \mathrm{kD}$, respectively, urinary losses have been implicated but not qualitatively demonstrated $(5,11)$.

In our population of children with NS, we have observed a well-described predisposition to primary peritonitis $(3,4,13,14)$. We have also observed that certain children are prone to recur- 
rent episodes of primary peritonitis. In our NS patient group with peritonitis, four of the seven children had two or more documented episodes of primary peritonitis, in all cases associated with relapse of their NS. The predominant isolate was the gram-positive bacteria Streptococcus pneumoniae. However, our patients represent a small population. As recently reviewed, $S$. pneumoniae is one of several causes of peritonitis in children with NS. Gram-negative organisms have been isolated in 6 to $29 \%$ of cases from large series, whereas streptococci other than S. pneumoniae were found in 4 to $8 \%$ of cases (15).

We demonstrated significantly greater excretion of both complement proteins I and B in relapse by patients with NS with a history of peritonitis than those without a history of peritonitis. In addition, those with peritonitis had lower plasma concentrations than those patients without peritonitis, and an inverse relationship was established between plasma and urinary concentrations of I. Depression of plasma levels of I and B in these patients, presumably due to urinary losses, may affect their ability to generate C3b needed to opsonize bacteria, and to effectively clear circulating immune complexes. This hypothesis is strengthened by the work of McLean et al. (11), who demonstrated decreased opsonization of Escherichia coli by serum from patients with NS, which was restored by the addition of exogenous B. In addition, reduced functional complement activity (16) and reduced $\mathrm{CR} 1$ receptor function and opsonization in factor Ideficient patients (17) have been shown to be restored by plasma infusion.

The conversion of the third component of complement, $\mathrm{C} 3$, to its activated form, C3b, through either alternative or classic pathway activation plays an integral part in the process of opsonization, phagocytosis, and the host defense system (Fig. 4) (18). The function of I includes the inactivation of $\mathrm{C} 3 \mathrm{~b}$, both in the fluid phase and on nonactivator surfaces (19). A deficiency or depression of I presumably impairs C3b inactivation, with consequent $B$ and $C 3$ depression, due to impaired regulation of this C3b amplification loop. The complement protein D, a serine protease with a molecular mass of approximately $24 \mathrm{kD}$, con-

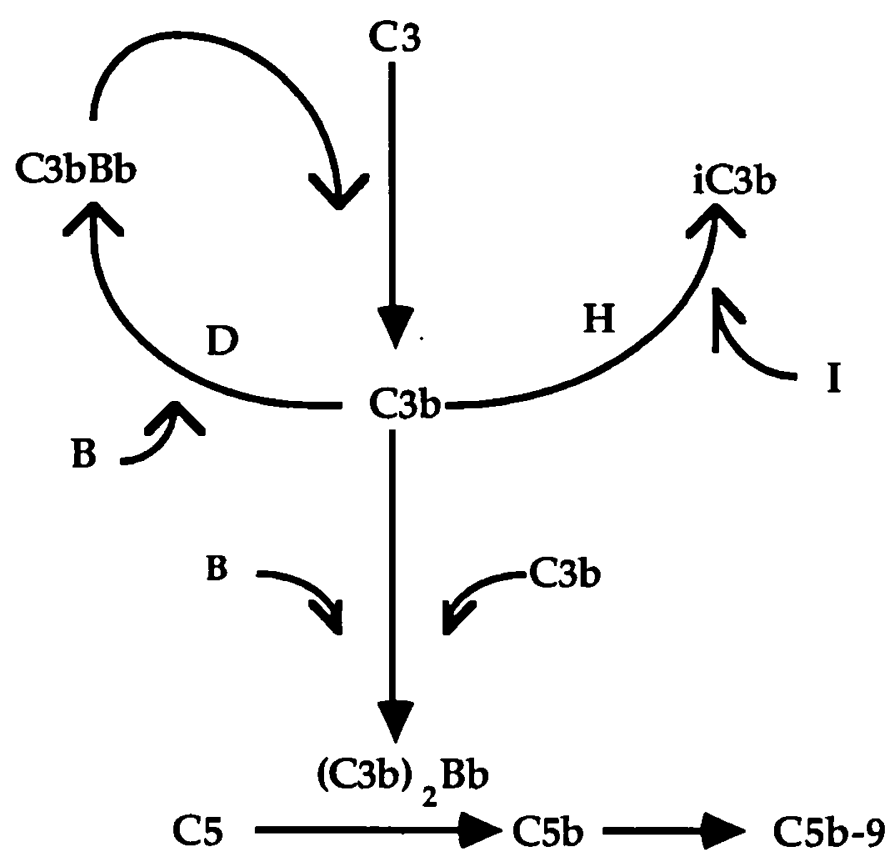

Fig. 4. Activation of the ACP. Initiation of $A C P$ activation is by the hydrolysis of $\mathrm{C} 3$ to $\mathrm{C} 3 \mathrm{~b}$. Once formed and covalently attached to a target acceptor surface, $\mathrm{C} 3 \mathrm{~b}$ is either rapidly inactivated by the regulatory proteins, including $\mathrm{I}$, or allowed to participate in the continuation of $\mathrm{ACP}$ activation, with the formation of the $\mathrm{C} 3$ convertase $(\mathrm{C} 3 \mathrm{bBb})$ and $\mathrm{C} 5$ convertase $(\mathrm{C} 3 \mathrm{~b})_{2} \mathrm{Bb}$. Formation of the $\mathrm{C} 5$ convertase results ultimately in the C5b-9, or membrane attack complex. tributes to the formation of the $\mathrm{C} 3$ convertase $\mathrm{C} 3 \mathrm{bBb}$, responsible for the amplification of $\mathrm{C} 3$ activation of the ACP (Fig. 4). In patients with chronic renal failure of diverse etiologies, Volanakis et al. (20) have demonstrated elevated serum concentrations of D. In nephrotic syndrome, however, serum levels were not significantly elevated. Interestingly, urinary concentrations were also not elevated, presumably because of proximal tubule catabolism. Because none of our patients had evidence of renal insufficiency, we would have expected normal serum concentrations of $D$ although they were not measured. Consequently, excessive cycling of the ACP due to elevated serum concentrations of D would not be an expected cause of $B$ depression in these patients.

The direct relationship of I and B depression with the development of peritonitis is unclear. Whereas homozygous I deficiency predisposes to a variety of recurrent bacterial infections (18-20), heterozygous I deficiency does not. However, in the case of active NS, numerous immunologic abnormalities and alterations occur, in addition to increased urinary losses of I and $\mathrm{B}$ and depression of plasma concentrations of these proteins. Defects of both humoral and cell-mediated immunity have been demonstrated in vitro and in vivo from children with active NS. These include impaired Ig synthesis with hypogammaglobulinemia, poor delayed-type hypersensitivity, decreased lymphoblast transformation, and increased suppressor T-cell activity (13).

We can only speculate why children with NS with a history of peritonitis have increased urinary losses of these proteins. As demonstrated in Table 2, patients with peritonitis as a group have clinically more severe disease, based upon their response to corticosteroids. Consequently, these patients may have increased urinary protein losses over time due to prolonged and unremitting disease. The pattern of urinary protein excretion, related to altered glomerular basement membrane permselectivity, may also be different in the group with peritonitis and therefore responsible for increased urinary losses of I and B. These questions remain to be resolved.

Acknowledgments. The authors thank Elizabeth Millar for her expert assistance in preparation of this manuscript and Dr. Larry Stitt from the Department of Epidemiology and Biostatistics at the University of Western Ontario, London, Ontario, for his help with the statistical analysis.

\section{REFERENCES}

1. Barness LA, Moll GH, Janeway CA 1950 Nephrotic syndrome, natural history of the disease. Pediatrics 5:486-503

2. Arneil AC 1961164 children with nephrosis. Lancet 2:1103-1110

3. Krensky AM, Inglefinger JR, Grupe WE 1982 Peritonitis in childhood nephrotic syndrome: 1970-1980. Am J Dis Child 136:732-736

4. Gorensek MJ, Lebel MH, Nelson JD 1988 Peritonitis in children with nephrotic syndrome. Pediatrics 81:849-856

5. Strife CF, Jackson EC, Forristal J, West CD 1986 Effect of the nephrotic syndrome on the concentration of serum complement components. Am J Kidney Dis 8:37-42

6. Oglesby TJ, Ueda A, Volanakis JE 1988 Radioassays for quantitation of intact complement proteins $\mathrm{C} 2$ and $\mathrm{B}$ in human serum. J Immunol Methods 110:55-62

7. Kolb WP, Morrow PR, Tamerius JD $1989 \mathrm{Ba}$ and Bb fragments of factor B activation: fragment production, biological activities, neoepitope expression, and quantitation in clinical samples. Complement Inflammation 6:175-204

8. Wyatt RJ, Forristal J, Davis CA, Coleman TH, West CD 1980 Control of serum $C 3$ levels by $\beta-1-\mathrm{H}$ and $\mathrm{C} 3 \mathrm{~b}$ inactivator. J Lab Clin Med 95:905-917

9. Julian BA, Wyatt RJ, McMorrow RG, Galla JH 1983 Serum complement proteins in IgA nephropathy. Clin Nephrol 20:251-258

10. Forristal J, Iitaka K, Vallota EH, West CD 1977 Correlations between serum factor B and C3b inactivator levels in normal subjects and in patients with infections, nephrosis and hypocomplementemic glomerulonephritis. Clin Exp Immunol 28:61-71

11. McLean RH, Forsgren A, Bjorksten B, Kim Y, Quie PG, Michael AF 1977 Decreased serum factor $B$ concentration associated with decreased opsonization of Escherichia coli in the idiopathic nephrotic syndrome. Pediatr Res 11:910-916

12. Michael AF, McLean RH, Roy LP, Westberg NG, Hoyer JR, Fish AJ, Vernier RL 1973 Immunologic aspects of the nephrotic syndrome. Kidney Int 3:105-115

13. Pahmer M 1940 Pneumococcal peritonitis in nephrotic and non-nephrotic children. J Pediatr 17:90-106 
14. Speck WT, Dresdale SS, McMillan RW 1974 Primary peritonitis and the nephrotic syndrome. Am J Surg 127:267-269

15. Matsell DG, Chesney RW, Wyatt RJ, Novello AC 1992 Infections of the child with renal disease. In: Patrick CC (ed) Infections in Immunocompromised Infants and Children. Churchill Livingstone, New York, pp 311-321

16. Barrett DJ, Boyle MDP 1984 Restoration of complement function in vivo by plasma infusion in factor I (C3b inactivator) deficiency. J Pediatr 104:76-81

17. Jepsen HH, Teisner B, Rasmussen JM, Srehag SE 1989 Reduced erythrocyte
CRI (CD35) receptor function and complement opsonization in factor Ideficient patients is restored by plasma infusion. Scand J Immunol 29:247-255

18. Frank MM, Fries LF 1991 The role of complement in inflammation and phagocytosis. Immunol Today 12:322-326

19. Harrison RA, Lachmann PJ 1980 The physiological breakdown of the third component of human complement. Mol Immunol 17:9-20

20. Volanakis JE, Barnum SR, Giddens M, Galla JH 1985 Renal filtration and catabolism of complement protein D. N Engl J Med 312:395-399

\section{Announcement}

\section{Charles E. Culpeper Foundation Scholarships in Medical Science}

The Charles E. Culpeper Foundation is currently accepting applications for its 1994 Scholarships in Medical Science Program designed to support the career development of academic physicians.

Up to three awards of $\$ 100,000$ per year for 3 years will be made to United States medical schools on behalf of candidates who are U.S. citizens, who have received their M.D. degree from a U.S. medical school in 1985 or later, and who are judged worthy of support by virtue of the quality of their research proposals. All scientific research relevant to human health is eligible for consideration. No institution may nominate more than one candidate.

In selecting awardees, emphasis will be on identifying young physicians with clear potential for making substantial contributions to science as academic physicians. Since January 1988, 18 physicians have been selected as Charles E. Culpeper Foundation Medical Scholars.

Deadline for applications is August 16,1993. Awards will be announced by January 14, 1994 for activation on or about July 1, 1994. Application forms and instructions may be obtained by contacting the Charles E. Culpeper Foundation at Financial Centre, 695 East Main Street, Suite 404, Stamford, CT 06901. 